\title{
Sensitive and Simultaneous Determination of Hydroquinone and Catechol in Water Using an Anodized Glassy Carbon Electrode with Polymerized 2-(Phenylazo) Chromotropic Acid
}

\author{
Miao Zhang, ${ }^{1}$ Chuang-ye Ge, ${ }^{2}$ Ya-feng Jin, ${ }^{3}$ Liang-bin Hu, ${ }^{1}$ Hai-zhen Mo, ${ }^{1}$ Xiao-bo Li $\mathbb{D},{ }^{3,4}$ \\ and Hao Zhang $\mathbb{D}^{1}$ \\ ${ }^{1}$ College of Food Science, Henan Institute of Science and Technology, Xinxiang 453003, China \\ ${ }^{2}$ Department of Applied Chemistry, Konkuk University, Chungju 380-701, Republic of Korea \\ ${ }^{3}$ Department of Chemistry and Chemical Engineering, Henan Institute of Science and Technology, Xinxiang 453003, China \\ ${ }^{4}$ State Key Laboratory of Luminescent Materials and Devices, South China University of Technology, Guangzhou 510641, China
}

Correspondence should be addressed to Xiao-bo Li; xbli@hist.edu.cn and Hao Zhang; zhanghao@hist.edu.cn

Received 23 May 2019; Revised 4 July 2019; Accepted 16 July 2019; Published 5 September 2019

Academic Editor: Cláudia G. Silva

Copyright () 2019 Miao Zhang et al. This is an open access article distributed under the Creative Commons Attribution License, which permits unrestricted use, distribution, and reproduction in any medium, provided the original work is properly cited.

Hydroquinone (HQ) and catechol (CT) are considered as environmental pollutants with high toxicity. We have developed a simple electrochemical sensor using an anodized glassy carbon electrode modified with a stable 2-(phenylazo) chromotropic acid(CH-) conducting polymer (PCH/AGCE). The PCH/AGCE sensor showed good electrocatalytic activity and reversibility towards the redox of HQ and CT in phosphate buffer solution (PBS, pH 7.0). The cyclic voltammetry (CV) in mixed solution of HQ and CT showed that the oxidation peaks of them became well resolved with a peak separation of $0.1 \mathrm{~V}$. The detection limits of HQ and CT were 0.044 and $0.066 \mu \mathrm{M}$, respectively, in a wide linear response range of $1-300 \mu \mathrm{M}$ for both. Moreover, the sensor displayed an excellent selectivity in the presence of common interferences. This study provided a simple, sensitive, and high recovery method for simultaneous and quantitative determination of HQ and CT in aqueous medium.

\section{Introduction}

HQ (1,4-benzenediol) and CT (1,2-benzenediol) have been widely used in cosmetics, pesticides, tanned leather, spices, medicines, and photography chemicals [1-3]. However, the release of $\mathrm{HQ}$ and $\mathrm{CT}$ into industrial wastewater [4] or smoke $[5,6]$ could cause severe pollution due to their high toxicity and low degradability [7-9]. Therefore, it is very important for the monitoring of excessive amount of $\mathrm{HQ}$ and CT. One of the main barricades is their coexistence and mutual interference because of their similar structures and behaviors [10]. Several analytical approaches including fluorescence [11], chromatography [12], chemiluminescence [13], spectrophotometry [14] have been applied for the simultaneous determination of HQ and CT. However, the aforementioned methods possess disadvantages such as the requirement of sophisticated laboratories, well-trained instrument operators, an expensive instrument, complicated analysis procedures, and time-consuming preparations [4]. Meanwhile, various electrochemical methods have attracted increasing attention due to their high sensitivity, simple operation, fast response, and low cost [4, 15-17]. Many modifiers such as mesoporous Pt [18], RGO-MWCNT [19], graphene/AuNPs/chitosan [20], Pt- $\mathrm{MnO}_{2}$ [21], carbon nanofragment [22], and conducting polymers (CPs) [23] have been introduced to enhance the electrode performance. Especially, CPs are preferential in view of their easy preparation and surface homogeneity as well as good reproducibility and stability [24]. Azobenzene compounds that consist of the azo group $(-\mathrm{N}=\mathrm{N}-)$ and large $\pi$-conjugated ring system have been adopted to prepare CPs for the detection of biomolecules such as dopamine $[25,26]$. Nevertheless, the electrochemical ability raised by the functional groups demands extensive investigation. 
In this study, we presented a sensitive and simple method for simultaneous determination of HQ and CT based on the electropolymerization of $\mathrm{CH}$, whose chemical structure is shown in Figure 1. $\mathrm{CH}$ is one of the azo dyes containing two $\mathrm{OH}$ and $\mathrm{SO}_{3} \mathrm{H}$ functional groups [27, 28], which make it a good electron donor for efficiently catalyzing the redox reactions of target molecules [4]. During the experiment, several experimental factors were optimized, such as the number of CVs sweeping for the polymerization and $\mathrm{pH}$ to obtain high selectivity and sensitivity [9]. The sensor exhibited good catalytic activity for the detection of HQ and CT, which has a low detection limit and wide dynamic range. We will try to implement outdoor field testing. The specific experimental is in the supplementary information (available here).

\section{Results and Discussion}

2.1. Formation and Characterization of the PCH Film. As shown in Figure 2(a), the electropolymerization of $\mathrm{CH}$ onto the AGCE was stimulated by taking the advantages of anodization process [29-31] and confirmed by the continuous growth of redox peaks in CVs. However, there was no polymer formed at the bare GCE, as shown in the inset. Herein, the $\mathrm{CH}$ molecules react with each other via $-\mathrm{OH}$ - bridge to form polymer [15] as shown in Figure S1.

We also studied the effect of $\mathrm{pH}$ in the range of 4.0-9.0 on the PCH/AGCE. From Figure 2(b), we can see the anodic peak potential $\left(E_{\mathrm{pa}}\right)$ shifted negatively with the increase of the $\mathrm{pH}$ and $E_{\mathrm{pa}}$ was linear against $\mathrm{pH}$ with the slope of $-32 \mathrm{mV} / \mathrm{pH}$. This value was verge on the half of theoretical value of $-59 \mathrm{mV} / \mathrm{pH}$ obtained from the Nernst equation, indicating that the ratio of protons and the transferred electrons involved in the $\mathrm{PCH}$ film was $1: 2$. Additionally, as displayed in Figure 2(c), the peak currents $\left(I_{\mathrm{pa}}\right.$ and $\left.I_{\mathrm{pc}}\right)$ increased with the scan rate grown and it was proportional to the scan rate in the range of $10-400 \mathrm{mV} / \mathrm{s}$ with the linear regression equations: $I_{\mathrm{pa}}(\mu \mathrm{A})=3.902 \mathrm{v} \quad(\mathrm{mV} / \mathrm{s})+9.605$ $\left(r^{2}=0.998\right) \quad$ and $I_{\mathrm{pc}} \quad(\mu \mathrm{A})=-1.606 \mathrm{v} \quad(\mathrm{mV} / \mathrm{s})-8.203$ $\left(r^{2}=0.996\right)$, respectively. The result indicated that the redox process of PCH was surface-controlled. The PCH film could be undergoing a redox process between naphthoquinone and naphthol [15, 32-34].

The EDX spectra displaying the peaks of $\mathrm{C}, \mathrm{N}, \mathrm{O}, \mathrm{Na}$, and $\mathrm{S}$ elements further prove the formation of $\mathrm{PCH}$ and SEM image showed an even surface with well-distributed nanoflakes (Figure 3).

2.2. Electrochemical Behavior of HQ and CT. The number of sweeping cycles was firstly optimized by means of peak current towards HQ and CT (100 $\mu \mathrm{M}$ of each) in PBS, which clearly displayed that 20 cycles exhibited the highest currents for both HQ and CT, as shown in Figure S2. Then, the electrochemical behavior of PCH/AGCE was studied using CV (Figure 4(a)) in PBS and a mixture of HQ and CT to compare with bare GCE and AGCE. Bare GCE showed a broad peak at $0.3 \mathrm{~V}$, as mentioned in many reports [22]. Both AGCE and PCH/AGCE could discriminate the oxidation

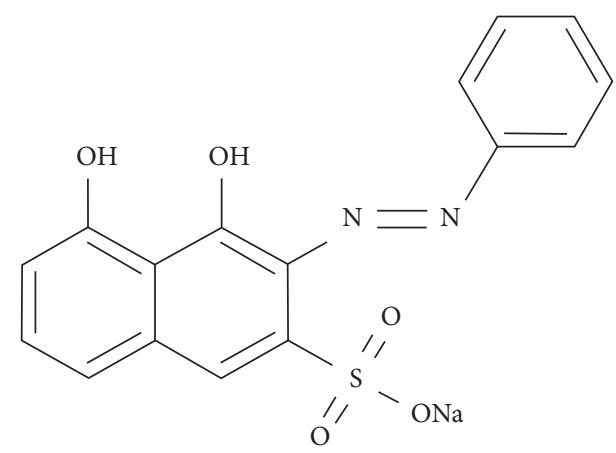

FIgURE 1: Chemical structure of $\mathrm{CH}$.

signals of HQ and CT with the same peak-to-peak potential separation $\left(\Delta E_{\mathrm{p}}\right)$ of $0.10 \mathrm{~V}$, which was sufficient for the simultaneous detection of them. Moreover, PCH/AGCE clearly showed higher currents resulting in a better catalytic sensitivity. It was also in coincidence with their DPV responses in Figure 4(b).

2.3. Effect of Scan Rate and $p H$. The effect of the scan rates on the electrochemical signals of $\mathrm{HQ}$ and $\mathrm{CT}$ was investigated by CV (Figure 5(a)) at the PCH/AGCE. The redox peak currents increased with the increasing scan rate. Both $I_{\mathrm{pa}}$ and $I_{\mathrm{pc}}$ of HQ and CT were linear with the square root of scan rate $\left(v^{1 / 2}\right)$ in a range of $10-500 \mathrm{mV} / \mathrm{s}$ suggesting the diffusion-controlled process with the equations of linear regression: $I_{\mathrm{pa}}(\mu \mathrm{A})=4.09 v^{1 / 2}(\mathrm{mV} / \mathrm{s})+8.38\left(r^{2}=0.99\right)$ and $I_{\mathrm{pa}}$ $(\mu \mathrm{A})=1.12 v^{1 / 2}(\mathrm{mV} / \mathrm{s})+1.16\left(r^{2}=0.97\right)$ for HQ and CT [24], respectively.

The CVs of HQ and CT in PBS with different $\mathrm{pH}$ values were also displayed in Figures 5(b) and 5(c). The peak potentials shifted negatively with increasing $\mathrm{pH}$ from 4.0 to 9.0; when the $\mathrm{pH}$ was between 4.0 and 6.0, the hydroxyl in dihydroxy benzenes will not ionized, which will reduce the adsorption capacity of the two dihydroxybenzene isomers; when the $\mathrm{pH}$ was increased from 7.0 to 9.0 , the increase in hydroxyl ion in the solution might also reduce the adsorption capacity of the two dihydroxybenzene isomers [32]. Considering the sensitivity of the measurement, $\mathrm{pH} 7.0$ was chosen as the optimal experimental condition and is exactly between 4 and 9 . The $E_{\mathrm{pa}}$ showed linear response towards $\mathrm{pH}$ with the corresponding regression equations: $E_{\mathrm{pa}}(\mathrm{V})=$ $0.568-0.059 \mathrm{pH}\left(r^{2}=0.99\right)$ and $E_{\mathrm{pa}}(\mathrm{V})=0.671-0.058 \mathrm{pH}$ $\left(r^{2}=0.98\right)$ for HQ and CT, respectively. The slopes of -59 and $-58 \mathrm{mV} / \mathrm{pH}$ clearly indicated that the number of involved electron and proton was equal in oxidation of $\mathrm{HQ}$ and CT [35].

2.4. Chronoamperometric Measurement for HQ and CT. The diffusion coefficient and catalytic rate constant of HQ and CT was calculated from chronoamperometry. The plots of current showed a good linear relationship with the reciprocal of the square root of time [36] (Figure 6(a)). The slope of the linear equation could be obtained by using the Cottrell equation: 


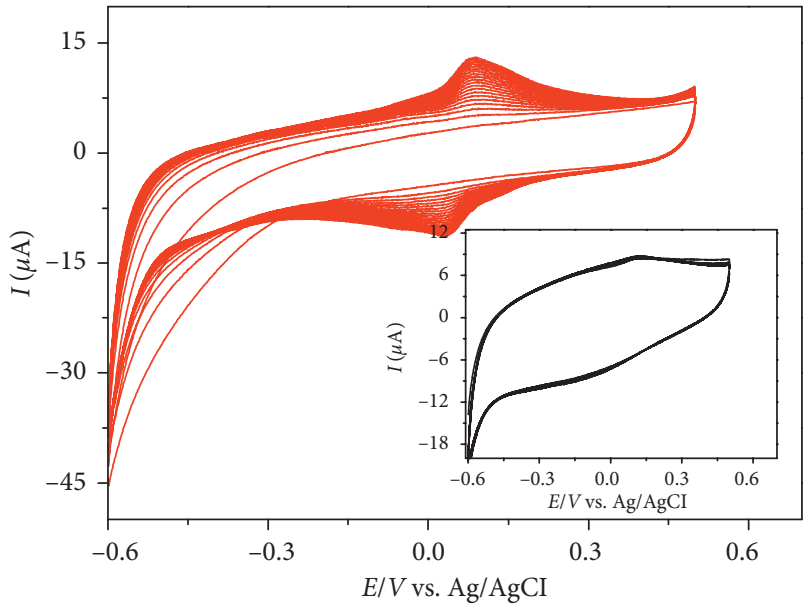

(a)

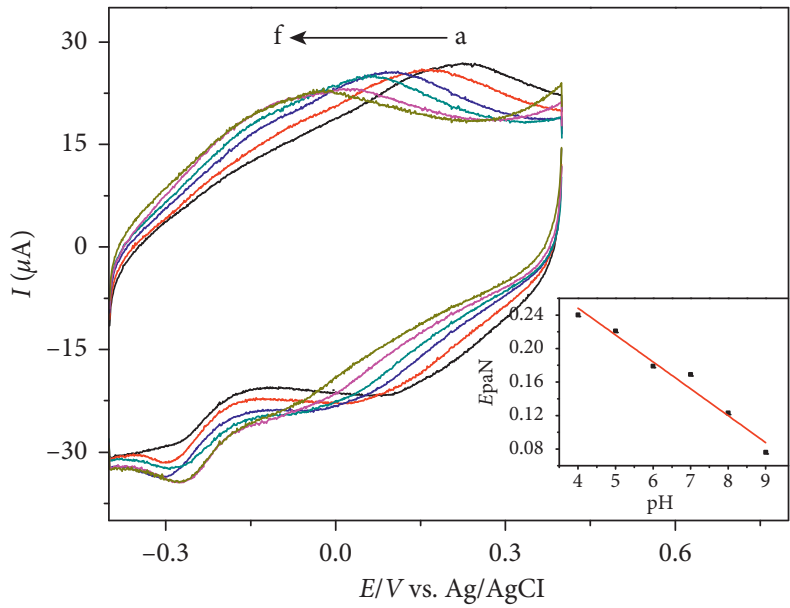

(b)

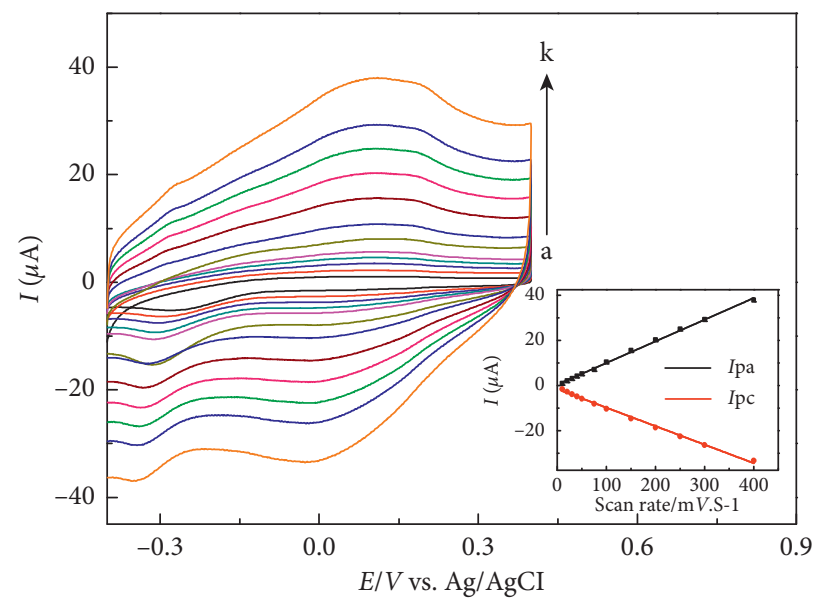

(c)

Figure 2: (a) CVs of the electropolymerization of $\mathrm{CH}$ onto the AGCE in 0.1 M PBS (pH 7.0). Inset shows CVs for bare GCE. Scan rate: $100 \mathrm{mV} / \mathrm{s}$. (b) CV of the PCH/AGCE in PBS with different $\mathrm{pH}$ values (a-f: 4.0, 5.0, 6.0, 7.0, 8.0, and 9.0). Scan rate: $100 \mathrm{mV} / \mathrm{s}$. (c) CVs of the $\mathrm{PCH} / \mathrm{AGCE}$ in $0.1 \mathrm{M}$ PBS (pH 7.0) at various scan rates $(a-k: 10,20,30,40,50,75,100,150,200,300$, and $400 \mathrm{mV} / \mathrm{s})$. Inset shows plots of $I_{\mathrm{pa}}$ and $I_{\mathrm{pc}}(\mu \mathrm{A})$ versus the scan rate $(\mathrm{mV} / \mathrm{s}) \mathrm{U}+002 \mathrm{e}$.

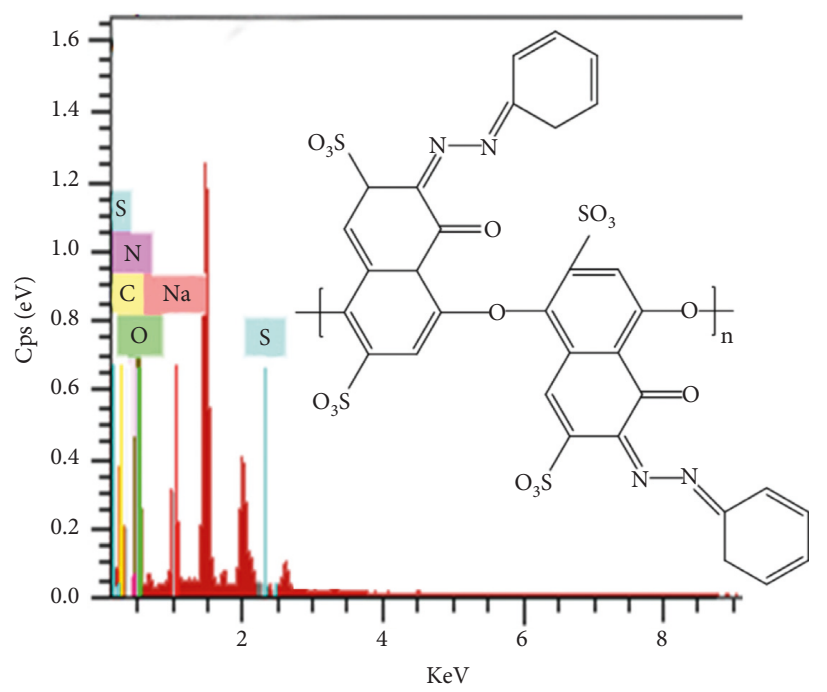

(a)

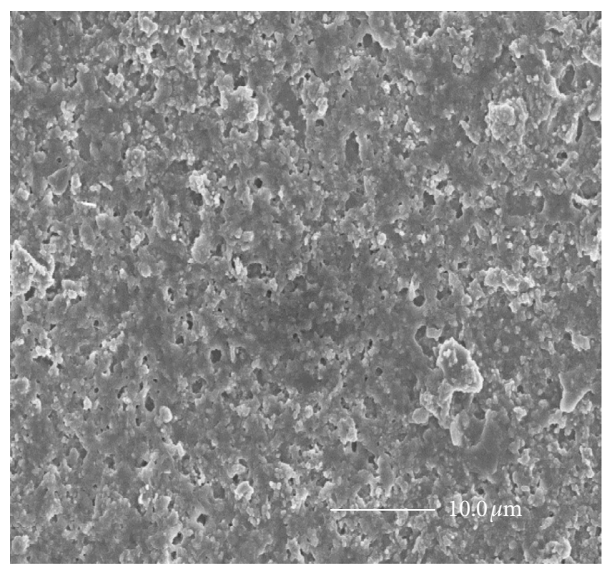

(b)

Figure 3: (a) EDS spectra and chemical structure (inset) of PCH. (b) SEM image of PCH film. 


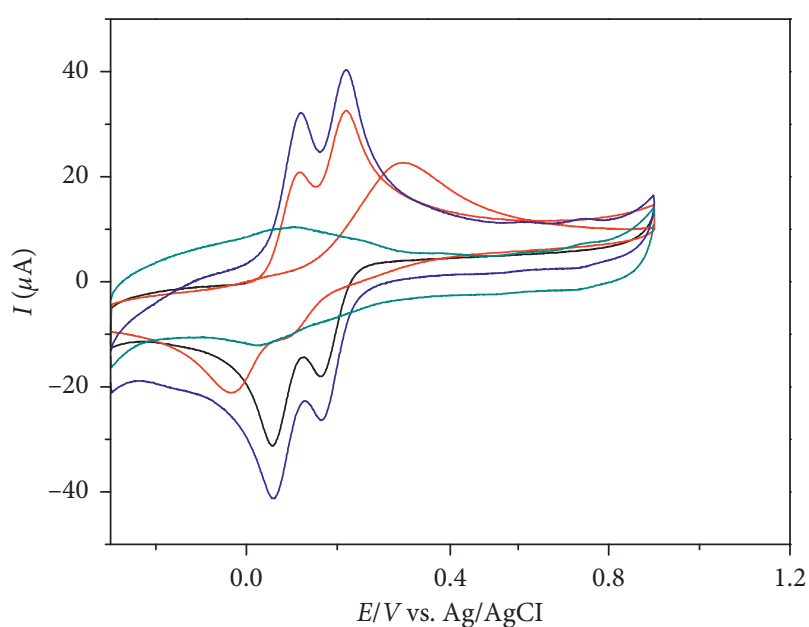

$\begin{array}{ll}- \text { AGCE in mixture } & \text { PCH/AGCE in mixture } \\ - \text { GCE in mixture } & \text { PCH/AGCE in PBS }\end{array}$

(a)

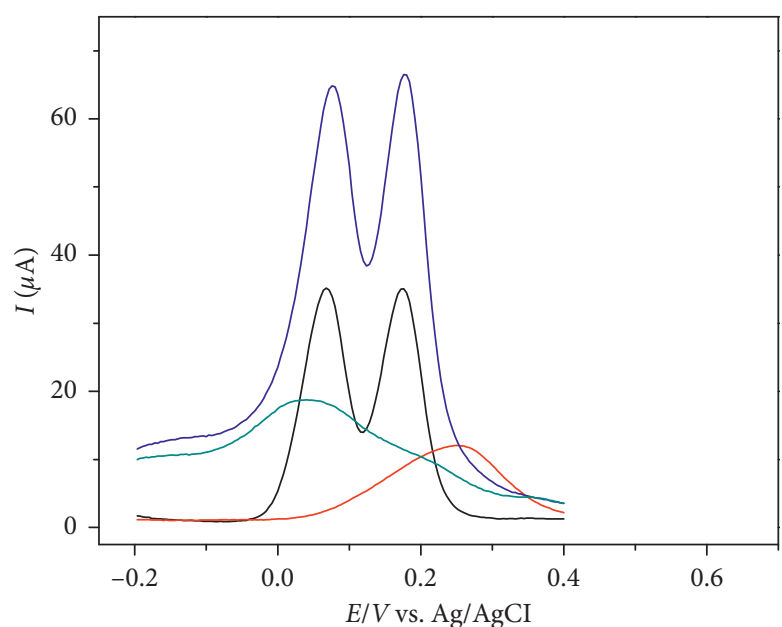

- AGCE in mixture - PCH/AGCE in mixture

— GCE in mixture _ PCH/AGCE in PBS

(b)

Figure 4: (a) CVs and (b) DPVs of bare GCE, AGCE, and PCH/AGCE in PBS (pH 7.0) and a mixture of HQ and CT (0.5 mM of each in PBS, $\mathrm{pH}$ 7.0). Scan rate: $100 \mathrm{mV} / \mathrm{s}$.

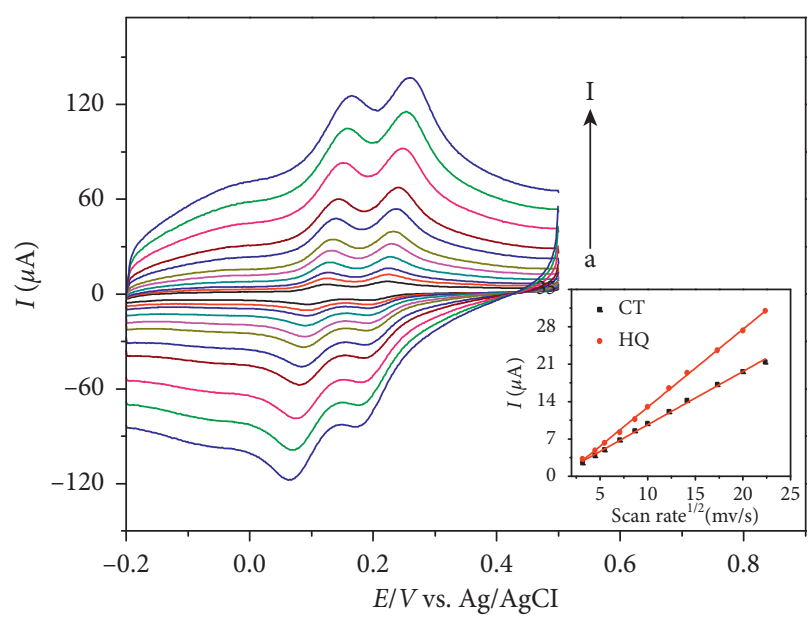

(a)

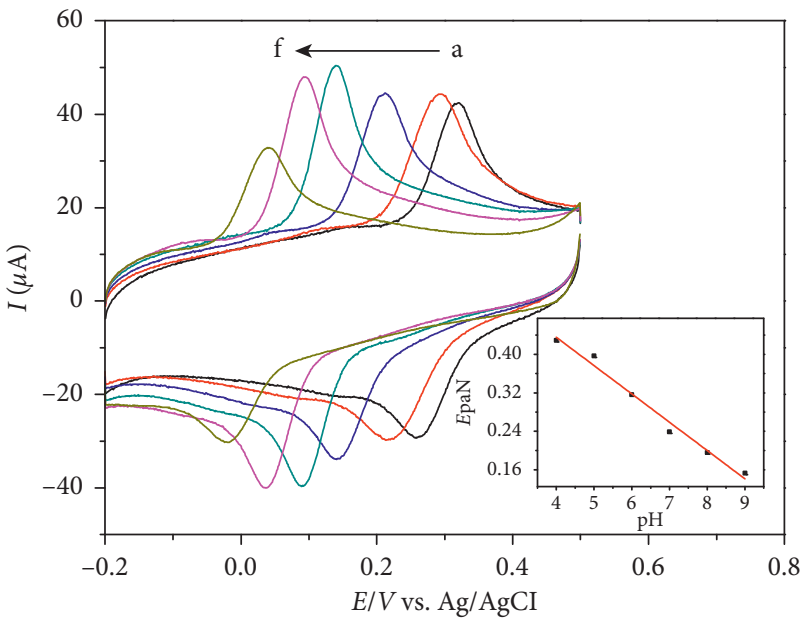

(b)

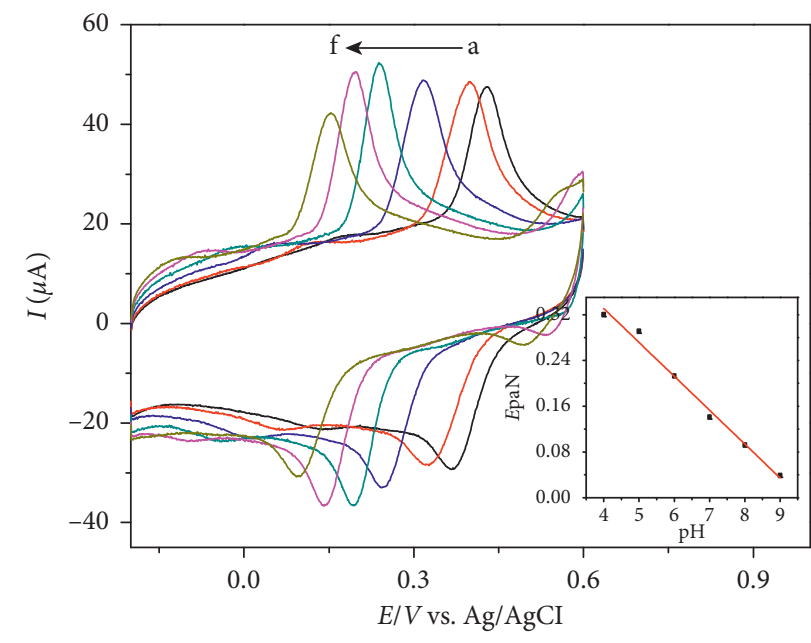

(c)

Figure 5: (a) CVs for the mixture solution of HQ and CT (0.5 mM each) in PBS (pH 7.0) at PCH/AGCE with different scan rates ( $a \longrightarrow$ 1: 10, 20, 30, $40,50,75,100,150,200,300,400$, and $500 \mathrm{mV} / \mathrm{s}$ ). The inset shows a plot of $I_{\mathrm{pa}}$ vs. the square root of the scan rate for HQ and CT. CVs of (b) CT $(0.5 \mathrm{mM})$ and $(\mathrm{c}) \mathrm{HQ}(0.5 \mathrm{mM})$ at the PCH/AGCE with different $\mathrm{pH}$ values $(a \longrightarrow f: 4,5,6,7,8$, and 9$)$ at a scan rate of $100 \mathrm{mV} / \mathrm{s}$. The inset shows plots of $E_{\mathrm{pa}}$ vs. $\mathrm{pH}$. 


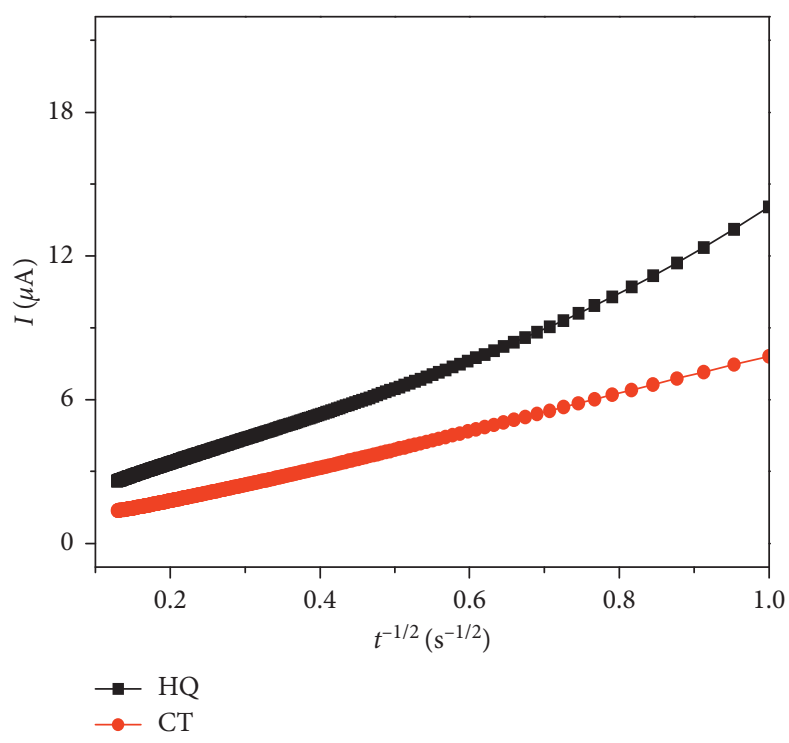

(a)

Figure 6: (a) Dependency of transient current on $t^{-1 / 2}$.

$$
I=n F A D^{1 / 2} C \pi^{-1 / 2} t^{-1 / 2}
$$

where $n$ is the number of transferred electrons; $F$ is the Faraday constant; $A$ is the proportion of the electrode; $D$ is the diffusion coefficient of active substance; $C$ is the initial molar concentration; and $t$ is the running time $[37,38]$.

From the resulting slope, the $D$ value of the HQ and CT was obtained to be $1.121 \times 10^{-5}$ and $9.170 \times 10^{-6} \mathrm{~cm}^{2} \mathrm{~s}^{-1}$, respectively.

Chronoamperometry was also be used to measure the catalytic rate constants [37] from the following equation:

$$
I_{\text {cat }} / I_{\mathrm{d}}=\gamma^{1 / 2} \pi^{1 / 2}=\pi^{1 / 2}(k C t),
$$

where $I_{\text {cat }}$ and $I_{\mathrm{d}}$ were the currents of the PCH/AGCE in the presence and absence of HQ and CT; $\gamma=k C t$ is the error function; $k$ is the catalytic rate constant; $C$ is the concentration of HQ and CT, and $t$ is the running time (s) [39].

From the slope of the $I_{\text {cat }} / I_{\mathrm{d}}$ vs. $t^{1 / 2}$ plot, as shown in Figure $6(\mathrm{~b})$, the $k$ value was obtained to be $1.57 \times 10^{2}$ and $1.51 \times 10^{2} \mathrm{~cm}^{3} \cdot \mathrm{mol}^{-1} \cdot \mathrm{s}^{-1}$ of HQ and CT in the concentration range of 0.1 to $0.4 \mathrm{mM}$, respectively.

2.5. Simultaneous and Selective Detection of HQ and CT at the PCH/AGCE. The prominent electrocatalytic performance of the PCH/AGCE was expected for the selective detection of HQ and CT. Figure 7(a) showed DPVs at different concentrations of $\mathrm{HQ}$ on the PCH/AGCE in the presence of a constant concentration of CT $(50 \mu \mathrm{M})$. The peak current of the HQ increased linearly with increasing concentration while the CT remained constant. Similarly, when the HQ concentration was fixed, the $I_{\mathrm{pa}}$ of CT increases with increasing concentration, while the $I_{\mathrm{pa}}$ of HQ remains almost constant (Figure 7(b)). The standard curve of $I_{\mathrm{pa}}$ vs. [HQ] and $I_{\mathrm{pa}}$ vs. [CT] is shown in the insets of Figures $7(\mathrm{a})$

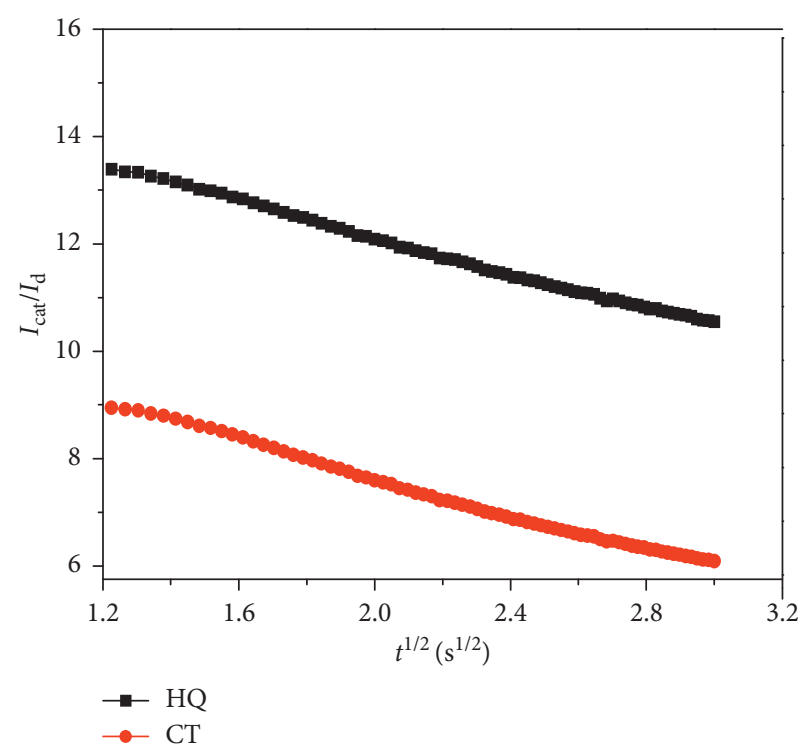

(b)

(b) Chronoamperometric measurements of $I_{\text {catal }} / I_{\mathrm{d}}$ and $t^{1 / 2}$.

and $7(\mathrm{~b})$, respectively, corresponding to the equations of linear regression: $I_{\mathrm{pa}}(\mu \mathrm{A})=8.17 \times[\mathrm{HQ}] \quad(\mu \mathrm{M})+9.26$ $\left(r^{2}=0.93\right)$ and $I_{\mathrm{pa}}(\mu \mathrm{A})=4.78 \times[\mathrm{CT}](\mu \mathrm{M})+3.46\left(r^{2}=0.98\right)$, respectively. The detection limit $(S / N=3)$ of HQ and CT was calculated to be 0.044 and $0.066 \mu \mathrm{M}$, respectively.

Figure 7(c) showed the DPVs for detection of HQ and $\mathrm{CT}$ at PCH/AGCE simultaneously. The $I_{\mathrm{pa}}$ of both HQ and $\mathrm{CT}$ at the PCH/AGCE sensor increased as their concentrations increased, but the peak potential hardly changed. The dynamic linear ranges of both HQ and CT were 20$300 \mu \mathrm{M}$, with following equations of linear regression: $I_{\mathrm{pa}}$ $(\mu \mathrm{A})=3.68 \times[\mathrm{HQ}](\mu \mathrm{M})+1.18\left(r^{2}=0.99\right)$ and $I_{\mathrm{pa}}(\mu \mathrm{A})=$ $3.538 \times[\mathrm{CT}](\mu \mathrm{M})+0.48\left(r^{2}=0.99\right)$, respectively. The detection limits were 0.052 and $0.073 \mu \mathrm{M}$ of HQ and CT, respectively.

These demonstrated that the PCH/AGCE sensor can be successfully adapted to the detection of HQ and CT simultaneously and can rival the analytical performance of other reported sensors; the summary is shown in Table 1. Therefore, the PCH/AGCE sensor is advantageous for detecting both HQ and CT without any significant mutual interference.

2.6. Repeatability, Stability, and Interference Analysis. Electrochemical repeatability of PCH/AGCE was measured by $\mathrm{CV}$ for 30 consecutive cycles with a range of -0.1 to $+0.5 \mathrm{~V}$ in the mixture of HQ and CT $(0.1 \mathrm{mM}$ each, PBS, $\mathrm{pH}$ 7.0). The relative standard deviation (RSD) of the oxidation currents of both HQ and CT was about $2.56 \%$ and $3.03 \%$, respectively, which proved the excellent repeatability of the PCH/AGCE sensor. Additionally, the oxidation peak currents of $\mathrm{HQ}$ and $\mathrm{CT}$ at the $\mathrm{PCH} / \mathrm{AGCE}$ sensor was decreased by only $3.5 \%$ and $4.0 \%$ of their initial values even though the PCH/AGCE sensor was stored in PBS ( $\mathrm{pH} 7.0$ ) for a week at $4^{\circ} \mathrm{C}$ in a refrigerator. This clearly shows that 


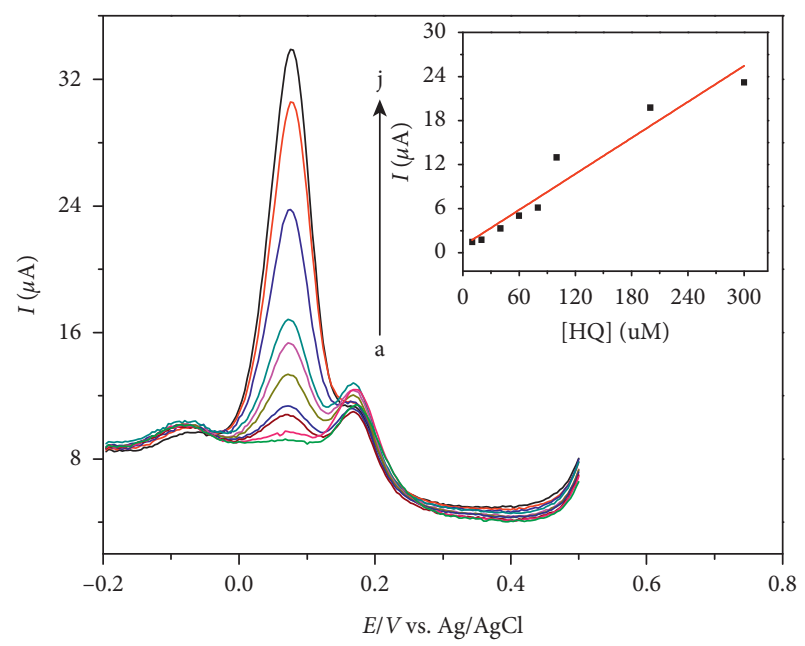

(a)

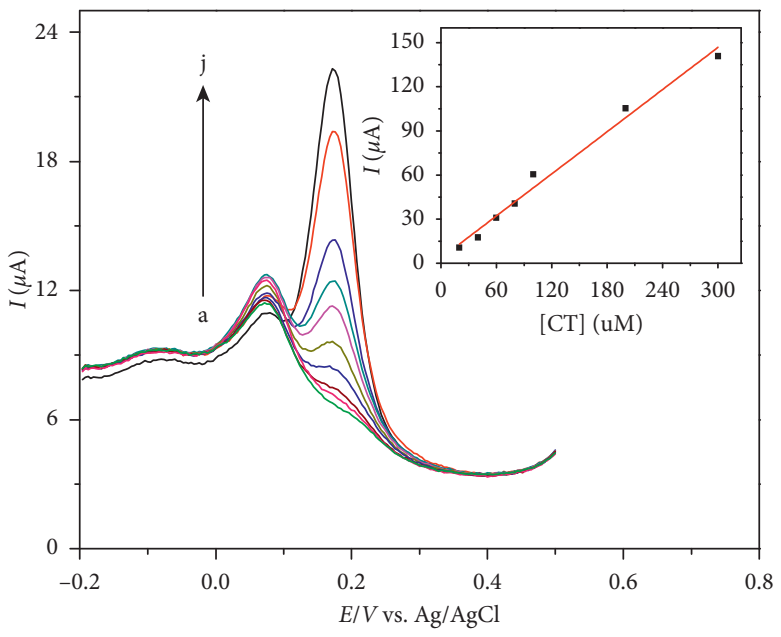

(b)

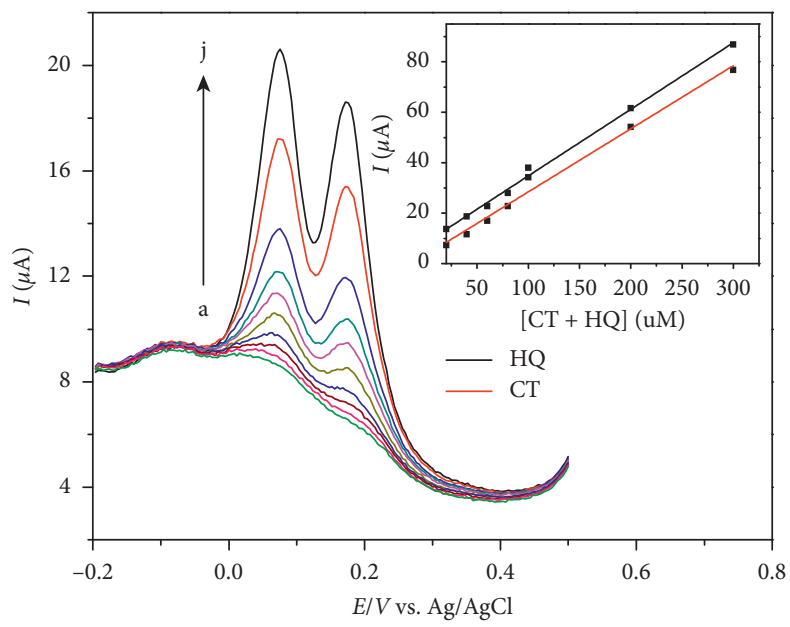

(c)

Figure 7: DPV responses at PCH/AGCE in PBS (pH 7.0) containing (a) $50 \mu \mathrm{M}$ of CT and different concentrations of HQ ( $a \longrightarrow j: 0,1$, $5,10,20,30,40,60,80,100,200$, and $300 \mu \mathrm{M})$; (b) $50 \mu \mathrm{M}$ of HQ and different concentrations of CT $(a \longrightarrow j: 0,1,5,10,20,30,40,60,80$, $100,200$, and $300 \mu \mathrm{M})$; (c) mixture of different concentrations of HQ and CT $(a \longrightarrow j: 0,1,5,10,20,30,40,60,80,100,200$, and $300 \mu \mathrm{M})$. Inset: plots of $I_{\mathrm{pa}}$ as a function of [HQ] or [CT].

TABle 1: Analytical performance of sensors reported in the literature for the detection of HQ and CT.

\begin{tabular}{|c|c|c|c|c|}
\hline Sensors & Detection method & Linear range $\mathrm{HQ} /(\mu \mathrm{M}) \mathrm{CT} /(\mu \mathrm{M})$ & Detection limit $(\mathrm{HQ} / \mathrm{CT}) / \mu \mathrm{M}$ & Ref. \\
\hline MOF-ERGO & DPV & $\begin{array}{l}0.1-566 \\
0.1-476\end{array}$ & $0.1 / 0.1$ & {$[7]$} \\
\hline pDNPH/AGCE & DPV & $\begin{array}{l}20-250 \\
20-250\end{array}$ & $0.75 / 0.76$ & {$[9]$} \\
\hline TH-GO/GCE & DPV & $\begin{array}{l}1-200 \\
1-200\end{array}$ & $0.02 / 0.025$ & {$[17]$} \\
\hline (NGB) MCPE & DPV & $\begin{array}{l}20-90 \\
20-90\end{array}$ & $0.19 / 0.20$ & {$[18]$} \\
\hline PBCB-modified AGCE & DPV & $\begin{array}{l}5-250 \\
5-250\end{array}$ & $0.06 / 0.05$ & [19] \\
\hline PEB/AGCE & DPV & $\begin{array}{l}1-100 \\
1-100\end{array}$ & $0.13 / 0.12$ & [23] \\
\hline SPCE/GO & DPV & $\begin{array}{l}1-312 \\
1-350\end{array}$ & $0.27 / 0.182$ & [28] \\
\hline $\mathrm{PB} / \mathrm{SPCE}$ & DPV & $\begin{array}{l}4-90 \\
1-90\end{array}$ & $0.12 / 0.42$ & [38] \\
\hline
\end{tabular}


TABLE 1: Continued.

\begin{tabular}{|c|c|c|c|c|}
\hline Sensors & Detection method & Linear range $\mathrm{HQ} /(\mu \mathrm{M}) \mathrm{CT} /(\mu \mathrm{M})$ & Detection limit $(\mathrm{HQ} / \mathrm{CT}) / \mu \mathrm{M}$ & Ref. \\
\hline $\mathrm{Pal} / \mathrm{NGE}$ & DPV & $\begin{array}{l}2-50 \\
1-50\end{array}$ & $0.8 / 0.13$ & {$[40]$} \\
\hline MCPE & DPV & $\begin{array}{l}20-180 \\
20-180\end{array}$ & $0.20 / 0.16$ & {$[41]$} \\
\hline MOF-rGO & DPV & $\begin{array}{c}10-1400 \\
4-1000\end{array}$ & $0.66 / 0.4$ & {$[42]$} \\
\hline $\mathrm{CuO}-\mathrm{CNF} / \mathrm{GCE}$ & $\mathrm{CV} / \mathrm{DPV}$ & $\begin{array}{c}3-80 \\
0-150\end{array}$ & $1 / 2$ & {$[43]$} \\
\hline PMMA_G_F & SWV & $\begin{array}{l}370-2680 \\
150-1670\end{array}$ & $270 / 170$ & {$[44]$} \\
\hline GCE & DPV & $\begin{array}{l}0.5-3.0 \\
0.5-3.0\end{array}$ & $0.06 / 0.06$ & {$[45]$} \\
\hline CNFs-Sm ${ }_{2} \mathrm{O}_{3} / \mathrm{GCE}$ & DPV & $\begin{array}{l}1-500 \\
1-500\end{array}$ & $0.09 / 0.07$ & {$[46]$} \\
\hline PPGE & DPV & $\begin{array}{l}2-200 \\
2-200\end{array}$ & $1.17 / 1.32$ & [47] \\
\hline Au3@Pd6/GCE & DPV & $4-500$ & 0.63 & {$[48]$} \\
\hline $\mathrm{PCH} / \mathrm{AGCE}$ & DPV & $\begin{array}{l}1-300 \\
1-300\end{array}$ & $0.044 / 0.066$ & This work \\
\hline
\end{tabular}

Note: MOF-ERGO: MOF-199 (MOF) and graphene oxide (GO); pDNPH/AGCE: 2,4-dinitrophenylhydrazine (DNPH), and it was electropolymerized on the surface of an anodized glassy carbon electrode; TH-GO/GCE: thionine/graphene oxide-modified glassy carbon electrodes; (NGB) MCPE: poly(naphthol green B)-modified carbon paste electrode; PBCB-modified AGCE: poly (brilliant cresyl blue)-modified activated glassy carbon electrode; PEB/AGCE: poly(Evans blue-) (PEB-) modified anodized glassy carbon electrode; PB-SPCE: prussian blue-modified screen-printed carbon electrode; Pal/NGE: nitrogendoped graphene (NGE) and palygorskite (Pal); Poly(glycine) MCPE: poly(glycine)- modified carbon paste electrode; SPCE/aGO: activated graphene oxide(aGO-) modified screen-printed carbon electrode (SPCE); MOF-rGO: reduced graphite oxide (rGO) incorporated into a metal organic framework (MOF); $\mathrm{CuO}-\mathrm{CNF} / \mathrm{GCE}$ : copper oxide and carbon nanofragment-modified glassy carbon electrode; PMMA_G_F: polymethylmethacrylate and graphite foams; GCE: glass carbon electrode; $\left.\mathrm{CNFs}-\mathrm{Sm}_{2} \mathrm{O}_{3} / \mathrm{GCE}\right)$ : $\mathrm{CNFs}-\mathrm{Sm}_{2} \mathrm{O}_{3}$ nanocomposite-modified glassy carbon electrode; PPGE: pretreated pencil graphite electrode; Au3@Pd6/GCE: Au3@Pd6 (nAu:nPd=3:6) modified the glassy carbon electrode (Au3@Pd6/GCE).

TABLE 2: Estimation of the oxidation current ratios of HQ and CT in the absence and presence of interferences.

\begin{tabular}{|c|c|c|}
\hline Interferences & Current ratios (HQ) & Current ratios $(\mathrm{CT})$ \\
\hline Resorcinol & 1.00 & 1.00 \\
\hline 2-Nitrophenol & 0.96 & 0.98 \\
\hline 3-Nitrophenol & 0.95 & 0.97 \\
\hline 4-Nitrophenol & 0.93 & 0.96 \\
\hline Bisphenol A & 1.00 & 1.00 \\
\hline 4-Acetamidophenol & 0.99 & 0.99 \\
\hline $\mathrm{NH}_{4}^{+}$ & 1.00 & 1.00 \\
\hline $\mathrm{Na}^{+}$ & 0.98 & 0.99 \\
\hline $\mathrm{Cl}^{-}$ & 1.00 & 1.00 \\
\hline $\mathrm{NO}_{3}^{-}$ & 0.99 & 1.00 \\
\hline $\mathrm{SO}_{4}{ }^{2-}$ & 1.00 & 0.99 \\
\hline
\end{tabular}

TABLE 3: Estimation of HQ and CT in local tap water and lake water samples.

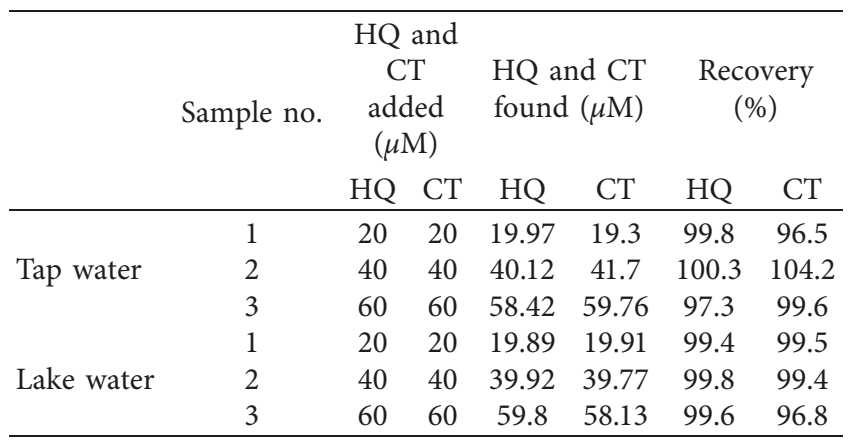

the chemical composition of the PCH/AGCE sensor is highly stable.

The interference studies were examined with some organic compounds and inorganic ions. We measured the oxidation peaks of the mixture of HQ and CT $(100 \mu \mathrm{M}$ each) in the absence and presence of more than 10-fold excess of resorcinol, 2-nitrophenol, 3-nitrophenol, 4nitrophenol, and phenol [24] and 100-fold 4-acetamidophenol, bisphenol $\mathrm{A}, \mathrm{NH}_{4}{ }^{+}, \mathrm{Na}^{+}, \mathrm{SO}_{4}{ }^{2-}, \mathrm{Cl}^{-}$, and $\mathrm{NO}_{3}{ }^{-}$ions in PBS. The oxidation potential range of resorcinol, 2-nitrophenol, 3-nitrophenol, and 4-nitrophenol was $0.5-1.0 \mathrm{~V}$, which was higher than those of HQ and CT (Figure S3). The ratios of the anodic peak current of HQ and CT before and after adding interferences were measured and summarized in Table 2 . This clearly implied that there was no significant interference in the simultaneous and quantitative detection of HQ and CT.

2.7. Real Sample Analysis. Real sample analysis was performed to investigate the practical application of the PCH/AGCE sensor. The recovery experiments were conducted by DPV, and known concentrations of HQ and CT were added in local tap water and lake water samples (Figure S4). As summarized in Table 3, the recoveries of HQ and CT were $97.3-100.3 \%$ and $96.5-104.2 \%$, respectively. It indicated the practical applicability and reliability of the proposed method. 


\section{Conclusions}

In this work, we have developed a simple and sensitive electrochemical sensor for simultaneous detection of HQ and $\mathrm{CT}$ on the basis of PCH/AGCE. The characteristic behavior was tested by CV and the DPV; it clearly certifies that PCH/AGCE has a better electrocatalytic performance for both $\mathrm{CT}$ and HQ. The detection limits were 0.044 and $0.066 \mu \mathrm{M}$ for $\mathrm{HQ}$ and $\mathrm{CT}$, respectively. In comparison with GCE, the PCH/AGCE showed good stability, reproducibility, and practicability in the real sample. The obtained results revealed that $\mathrm{PCH}$ could be a promising candidate for the development of biosensing and other electrochemical applications.

\section{Data Availability}

The data used to support the findings of this study are available from the corresponding author upon request.

\section{Conflicts of Interest}

The authors declare that there are no conflicts of interest.

\section{Authors' Contributions}

Miao Zhang and Chuang-ye Ge contributed equally to this work.

\section{Acknowledgments}

This work was financially supported by the Program for Science and Technology Innovation Talents in Universities of Henan Province (18HASTIT037), Henan Technology System for Conventional Freshwater Fish Industries (S2018-10-G2), the open fund of the State Key Laboratory of Luminescent Materials and Devices in South China University of Technology (no. 2018-skllmd-09), and the Key Research Projects for Institutions of Higher Education from the Department of Education, Henan Province (no. 17A150010).

\section{Supplementary Materials}

Figure S1: eletropolymerization process and redox reaction of PCH. Figure S2: dependency of the oxidation peak currents of both HQ and CT with the variation of the number of $\mathrm{CV}$ cycles (i.e., the thickness of $\mathrm{PCH}$ film) obtained from the CV measurement of the mixture of HQ and CT $(100 \mu \mathrm{M}$ each) in PBS), scan rate $100 \mathrm{mV} / \mathrm{s}$. Figure S3: CVs of mixture containing HQ and CT $(100 \mu \mathrm{M})$ with 2nitrophenol, 3-nitrophenol, 4-nitrophenol, phenol, and resorcinol (1 mM each) at PCH/AGCE in PBS ( $\mathrm{pH} 7.0)$, scan rate $100 \mathrm{mV} / \mathrm{s}$. Figure S4: DPV profiles of tap water (A) and local lake water (B) containing CT and HQ with different concentrations $(0,20,40$, and $60 \mu \mathrm{M})$. (Supplementary Materials)

\section{References}

[1] R. S. Ribeiro, N. A. Fathy, A. A. Attia, A. M. T. Silva, J. L. Faria, and H. T. Gomes, "Activated carbon xerogels for the removal of the anionic azo dyes Orange II and Chromotrope $2 \mathrm{R}$ by adsorption and catalytic wet peroxide oxidation," Chemical Engineering Journal, vol. 195-196, pp. 112-121, 2012.

[2] M. Amiri, S. Ghaffari, A. Bezaatpour, and F. Marken, "Carbon nanoparticle-chitosan composite electrode with anion, cation, and neutral binding sites: dihydroxybenzene selectivity," Sensors and Actuators B: Chemical, vol. 162, no. 1, pp. 194-200, 2012.

[3] M. Galik, A. M. O’Mahony, and J. Wang, "Cyclic and squarewave voltammetric signatures of nitro-containing explosives," Electroanalysis, vol. 23, no. 5, pp. 1193-1204, 2011.

[4] P. S. Ganesh and B. E. Kumara Swamy, "Simultaneous electroanalysis of hydroquinone and catechol at poly(brilliant blue) modified carbon paste electrode: a voltammetric study," Journal of Electroanalytical Chemistry, vol. 756, pp. 193-200, 2015.

[5] T. Xie, Q. Liu, Y. Shi, and Q. Liu, "Simultaneous determination of positional isomers of benzenediols by capillary zone electrophoresis with square wave amperometric detection," Journal of Chromatography A, vol. 1109, no. 2, pp. 317-321, 2006.

[6] M. Luther, J. Parry, J. Moore et al., "Inhibitory effect of Chardonnay and black raspberry seed extracts on lipid oxidation in fish oil and their radical scavenging and antimicrobial properties," Food Chemistry, vol. 104, no. 3, pp. 1065-1073, 2007.

[7] Q. Chen, X. Li, X. Min et al., "Determination of catechol and hydroquinone with high sensitivity using MOF-graphene composites modified electrode," Journal of Electroanalytical Chemistry, vol. 789, pp. 114-122, 2017.

[8] N. Aravindan and M.V. Sangaranarayanan, "Differential pulse voltammetry as an alternate technique for over oxidation of polymers: application of electrochemically synthesized over oxidized poly (Alizarin Red S) modified disposable pencil graphite electrodes for simultaneous detection of hydroquinone and catechol," Journal of Electroanalytical Chemistry, vol. 789, pp. 148-159, 2017.

[9] N. S. Lopa, M. M. Rahman, H. Jang et al., "A glassy carbon electrode modified with poly(2,4-dinitrophenylhydrazine) for simultaneous detection of dihydroxybenzene isomers," Microchim. Acta, vol. 185, no. 1, pp. 1-9, 2018.

[10] H. Qi and C. Zhang, "Simultaneous determination of hydroquinone and catechol at a glassy carbon electrode modified with multiwall carbon nanotubes," Electroanalysis, vol. 17, no. 10, pp. 832-838, 2005.

[11] M. F. Pistonesi, M. S. Di Nezio, M. E. Centurión et al., "Simultaneous determination of hydroquinone, resorcinol, phenol, $m$-cresol and $p$-cresol in untreated air samples using spectrofluorimetry and a custom multiple linear regressionsuccessive projection algorithm," Talanta, vol. 83, no. 2, pp. 320-323, 2010.

[12] T. Zhou, J. Hou, D. Yuan et al., "Determination of triazine herbicides from honey samples based on hydrophilic molecularly imprinted resins followed by high performance liquid chromatography-tandem mass spectrometry," RSC Advances, vol. 6, no. 101, pp. 98663-98673, 2016.

[13] S. Xu, J. Li, X. Li et al., "A chemiluminescence resonance energy transfer system composed of cobalt(II), luminol, hydrogen peroxide and CdTe quantum dots for highly sensitive 
determination of hydroquinone," Microchimica Acta, vol. 183, no. 2, pp. 667-673, 2016.

[14] Z. Moldovan, D. E. Popa, I. G. David, M. Buleandra, and I. A. Badea, "A derivative spectrometric method for hydroquinone determination in the presence of kojic acid, glycolic acid, and ascorbic acid," Journal of Spectroscopy, vol. 2017, Article ID 6929520, 9 pages, 2017.

[15] X.-B. Li, M. M. Rahman, G.-R. Xu, and J.-J. Lee, "Highly sensitive and selective detection of dopamine at poly(chromotrope $2 \mathrm{~B}$ )modified glassy carbon electrode in the presence of uric acid and ascorbic acid," Electrochimica Acta, vol. 173, pp. 440-447, 2015.

[16] J. Fu, X. Tan, Z. Shi, X. Song, and S. Zhang, "Highly sensitive and simultaneous detection of hydroquinone and catechol using poly(mercaptoacetic acid)/exfoliated graphene composite film-modified electrode," Electroanalysis, vol. 28, no. 1, pp. 203-210, 2016.

[17] X. Li, G. Xu, X. Jiang, and J. Tao, "Highly sensitive and simultaneous determination of hydroquinone and catechol at thionine/graphene oxide modified glassy carbon electrodes," Journal of the Electrochemical Society, vol. 161, no. 9, pp. H464-H468, 2014.

[18] C. M. Kuskur, B. E. Kumara Swamy, and H. Jayadevappa, "Poly (naphthol green B) modified carbon paste electrode sensor for catechol and hydroquinone," Journal of Electroanalytical Chemistry, vol. 804, pp. 99-106, 2017.

[19] A. A. Shaikh, S. K. Saha, P. K. Bakshi, A. Hussain, and A. J. Saleh Ahammad, "Poly(brilliant cresyl blue)-modified electrode for highly sensitive and simultaneous determination of hydroquinone and catechol," Journal of the Electrochemical Society, vol. 160, no. 4, pp. B37-B42, 2013.

[20] C. Shan, H. Yang, D. Han, Q. Zhang, A. Ivaska, and L. Niu, "Graphene/AuNPs/chitosan nanocomposites film for glucose biosensing," Biosensors and Bioelectronics, vol. 25, no. 5, pp. 1070-1074, 2010.

[21] B. Unnikrishnan, P.-L. Ru, and S.-M. Chen, "Electrochemically synthesized Pt- $\mathrm{MnO}_{2}$ composite particles for simultaneous determination of catechol and hydroquinone," Sensors and Actuators B: Chemical, vol. 169, pp. 235-242, 2012.

[22] C. Zhang, L. Zeng, X. Zhu et al., "Electrocatalytic oxidation and simultaneous determination of catechol and hydroquinone at a novel carbon nano-fragment modified glassy carbon electrode," Analytical Methods, vol. 5, no. 9, pp. 2203-2208, 2013.

[23] C.-y. Ge, M. M. Rahman, X.-b. Li, and J.-J. Lee, "Simultaneous and interference-free detection of hydroquinone and catechol on poly (evans blue)-modified glassy carbon electrode," Journal of the Electrochemical Society, vol. 163, no. 10, pp. B556-B562, 2016.

[24] L. Wang, Y. Zhang, Y. Du, D. Lu, Y. Zhang, and C. Wang, "Simultaneous determination of catechol and hydroquinone based on poly (diallyldimethylammonium chloride) functionalized graphene-modified glassy carbon electrode," Journal of Solid State Electrochemistry, vol. 16, no. 4, pp. 1323-1331, 2012.

[25] X. Li and G. Xu, "Simultaneous determination of ranitidine and metronidazole in pharmaceutical formulations at pol$\mathrm{y}$ (chromotrope 2B) modified activated glassy carbon electrodes," Journal of Food and Drug Analysis, vol. 22, no. 3, pp. 345-349, 2014.

[26] X. Lin, Q. Zhuang, J. Chen, S. Zhang, and Y. Zheng, "Electrocatalytic property of poly-chromotrope $2 \mathrm{~B}$ modified glassy carbon electrode on dopamine and its application," Sensors and Actuators B: Chemical, vol. 125, no. 1, pp. 240-245, 2007.
[27] D.-M. Zhao, X.-H. Zhang, L.-J. Feng, L. Jia, and S.-F. Wang, "Simultaneous determination of hydroquinone and catechol at PASA/MWNTs composite film modified glassy carbon electrode," Colloids and Surfaces B: Biointerfaces, vol. 74, no. 1, pp. 317-321, 2009.

[28] M. M. Rahman, X.-B. Li, Y.-D. Jeon, H.-J. Lee, S. J. Lee, and J.-J. Lee, "Simultaneous determination of ranitidine and metronidazole at poly(thionine) modified anodized glassy carbon electrode," Journal of Electrochemical Science and Technology, vol. 3, no. 2, pp. 90-94, 2012.

[29] G. N. Kamau, "Surface preparation of glassy carbon electrodes," Analytica Chimica Acta, vol. 207, pp. 1-16, 1988.

[30] R. C. Engstrom, "Electrochemical pretreatment of glassy carbon electrodes," Analytical Chemistry, vol. 54, no. 13, pp. 2310-2314, 1982.

[31] K. Ravichandran and R. P. Baldwin, "Liquid chromatographic determination of hydrazines with electrochemically pretreated glassy carbon electrodes," Analytical Chemistry, vol. 55, no. 11, pp. 1782-1786, 1983.

[32] H. Yin, Q. Zhang, Y. Zhou et al., "Electrochemical behavior of catechol, resorcinol and hydroquinone at graphene-chitosan composite film modified glassy carbon electrode and their simultaneous determination in water samples," Electrochimica Acta, vol. 56, no. 6, pp. 2748-2753, 2011.

[33] V. J. Mayani, S. V. Mayani, and S. W. Kim, "A sustainable nanocomposite $\mathrm{Au}$ (salen)@CC for catalytic degradation of eosin Y and chromotrope 2R dyes," Scientific Reports, vol. 7, pp. 1-9, 2017.

[34] A. Cárdenas, M. Gómez, and C. Frontana, "Electrochemical method to quantify antioxidants employing cupric reducing antioxidant capacity, CUPRAC," Procedia Chemistry, vol. 12, pp. 62-65, 2014.

[35] H. Yao, Y. Sun, X. Lin, Y. Tang, and L. Huang, "Electrochemical characterization of poly(eriochrome black $\mathrm{T}$ ) modified glassy carbon electrode and its application to simultaneous determination of dopamine, ascorbic acid and uric acid," Electrochimica Acta, vol. 52, no. 20, pp. 6165-6171, 2007.

[36] S.-J. Liu, R. Zhang, L. Wang, and G.-J. Yang, "Mechanism of electrochemically polymerised acid chrome blue $\mathrm{K}$ and its application in copper ion detection," International Journal of Environmental Analytical Chemistry, vol. 94, no. 6, pp. 546-561, 2014.

[37] M. Jafarian, F. Forouzandeh, I. Danaee, F. Gobal, and M. G. Mahjani, "Electrocatalytic oxidation of glucose on $\mathrm{Ni}$ and $\mathrm{NiCu}$ alloy modified glassy carbon electrode," Journal of Solid State Electrochemistry, vol. 13, no. 8, pp. 1171-1179, 2009.

[38] H. Gharibi, S. Sadeghi, and F. Golmohammadi, "Electrooxidation of Ethanol on highly active and stable carbon supported $\mathrm{PtSnO}_{2}$ and its application in passive direct ethanol fuel cell: effect of tin oxide synthesis method," Electrochimica Acta, vol. 190, pp. 1100-1112, 2016.

[39] S. Z. Mohammadi, H. Beitollahi, and M. Mousavi, "Determination of hydroxylamine using a carbon paste electrode modified with graphene oxide nano sheets," Russian Journal of Electrochemistry, vol. 53, no. 4, pp. 374-379, 2017.

[40] Y. Wu, W. Lei, M. Xia et al., "Simultaneous electrochemical sensing of hydroquinone and catechol using nanocomposite based on palygorskite and nitrogen doped graphene," Applied Clay Science, vol. 162, pp. 38-45, 2018.

[41] K. V. Harisha, B. E. Kumara Swamy, and E. E. Ebenso, "Poly (glycine) modified carbon paste electrode for simultaneous determination of catechol and hydroquinone: a voltammetric 
study," Journal of Electroanalytical Chemistry, vol. 823, pp. 730-736, 2018.

[42] H. Wang, Q. Hu, Y. Meng et al., "Efficient detection of hazardous catechol and hydroquinone with MOF-rGO modified carbon paste electrode," Journal of Hazardous Materials, vol. 353, pp. 151-157, 2018.

[43] L. A. Alshahrani, L. Liu, P. Sathishkumar, J. Nan, and F. L. Gu, "Copper oxide and carbon nano-fragments modified glassy carbon electrode as selective electrochemical sensor for simultaneous determination of catechol and hydroquinone in real-life water samples," Journal of Electroanalytical Chemistry, vol. 815, pp. 68-75, 2018.

[44] C. Fernandez-Blanco, M. Mugica, M. A. Rodriguez-Perez, C. Garcia-Cabezón, and M. L. Rodriguez-Mendez, "Polymeric foams as the matrix of voltammetric sensors for the detection of catechol, hydroquinone, and their mixtures," Journal of Sensors, vol. 2018, Article ID 2714752, 9 pages, 2018.

[45] J. Fan, J. Pang, Y. Zhang, L. Zhang, W. Xu, and J. Wang, "Simultaneous detection of hydroquinone and catechol with decreasing $\mathrm{pH}$ at a bare glassy carbon electrode surface," Analytical Methods, vol. 11, no. 5, pp. 604-609, 2019.

[46] J. He, F. Qiu, Q. Xu, J. An, and R. Qiu, "A carbon nanofibers- $\mathrm{Sm}_{2} \mathrm{O}_{3}$ nanocomposite: a novel electrochemical platform for simultaneously detecting two isomers of dihydroxybenzene," Analytical Methods, vol. 10, no. 16, pp. 1852-1862, 2018.

[47] S. Nagarajan, R. Vairamuthu, R. Angamuthu, and G. Venkatachalam, "Electrochemical fabrication of reusable pencil graphite electrodes for highly sensitive, selective and simultaneous determination of hydroquinone and catechol," Journal of Electroanalytical Chemistry, vol. 846, Article ID 113156, 2019.

[48] T. Chen, J. Xu, M. Arsala et al., "Controlled synthesis of Au@ Pd core-shell nanocomposites and their application for electrochemical sensing of hydroquinone," Talanta, vol. 198, pp. 78-85, 2019. 

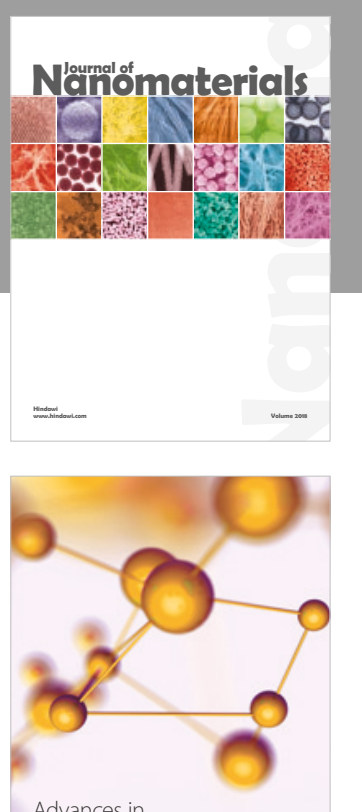

Physical Chemistry
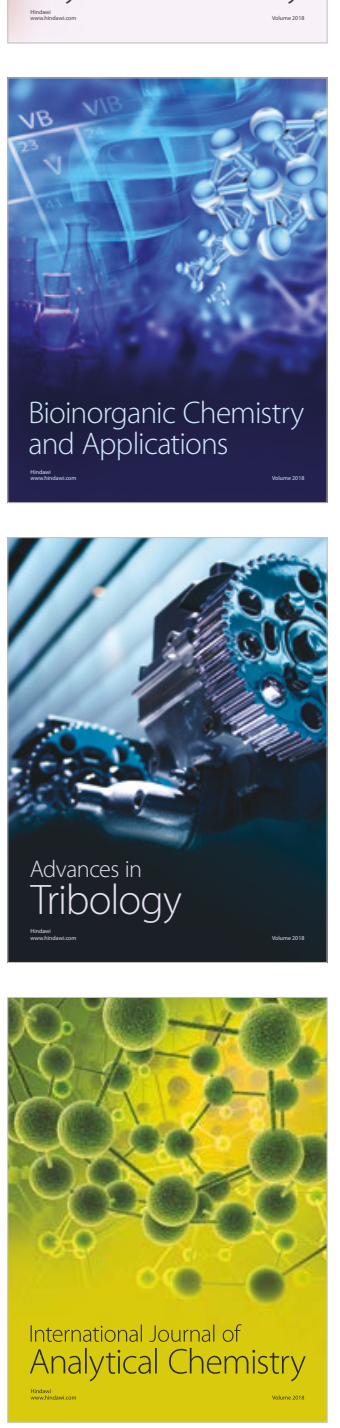

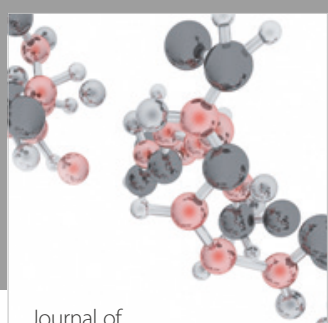

Analytical Methods

in Chemistry

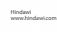

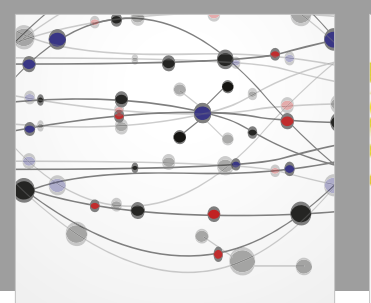

The Scientific World Journal

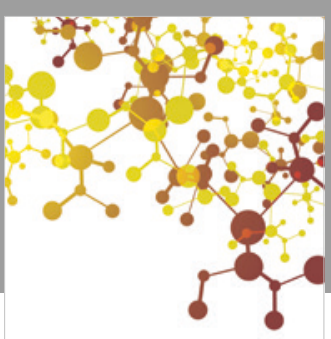

Journal of

Applied Chemistry
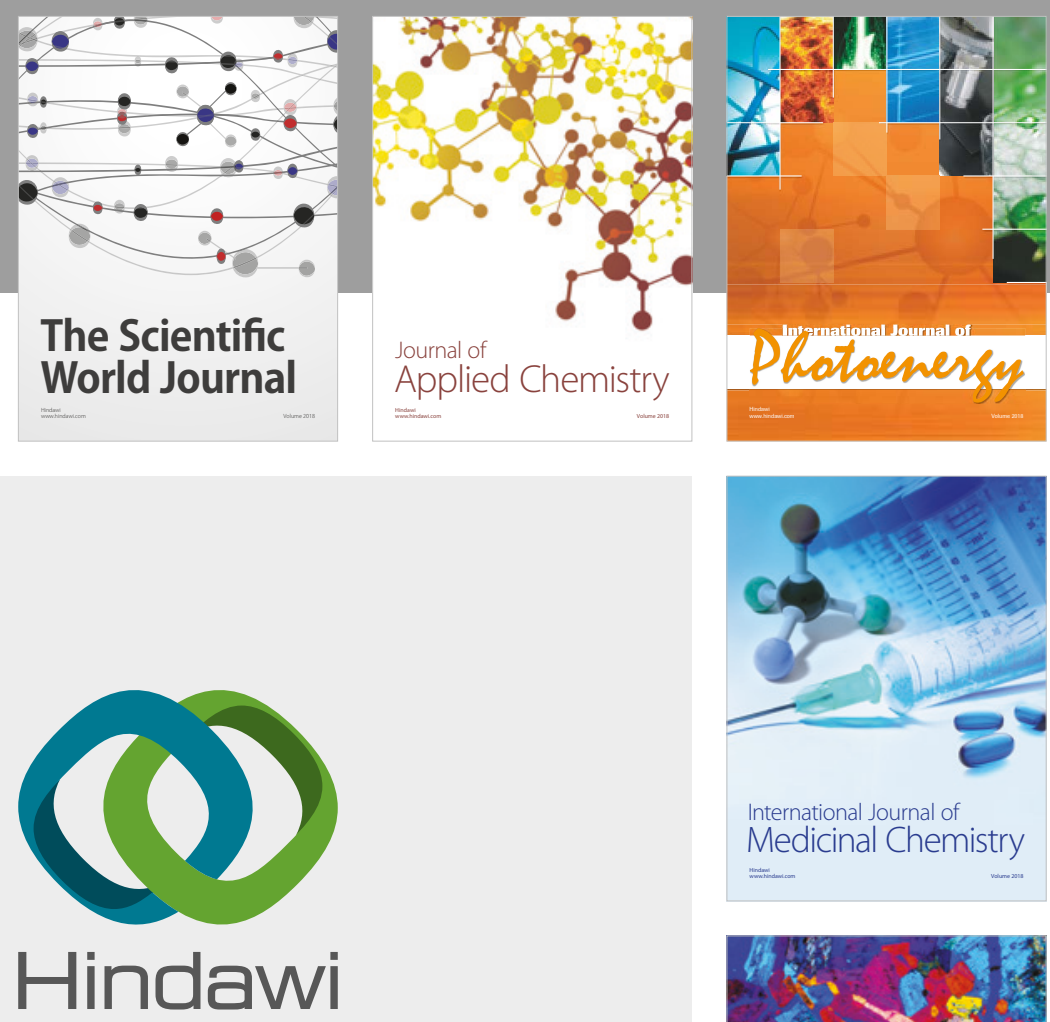

Submit your manuscripts at

www.hindawi.com
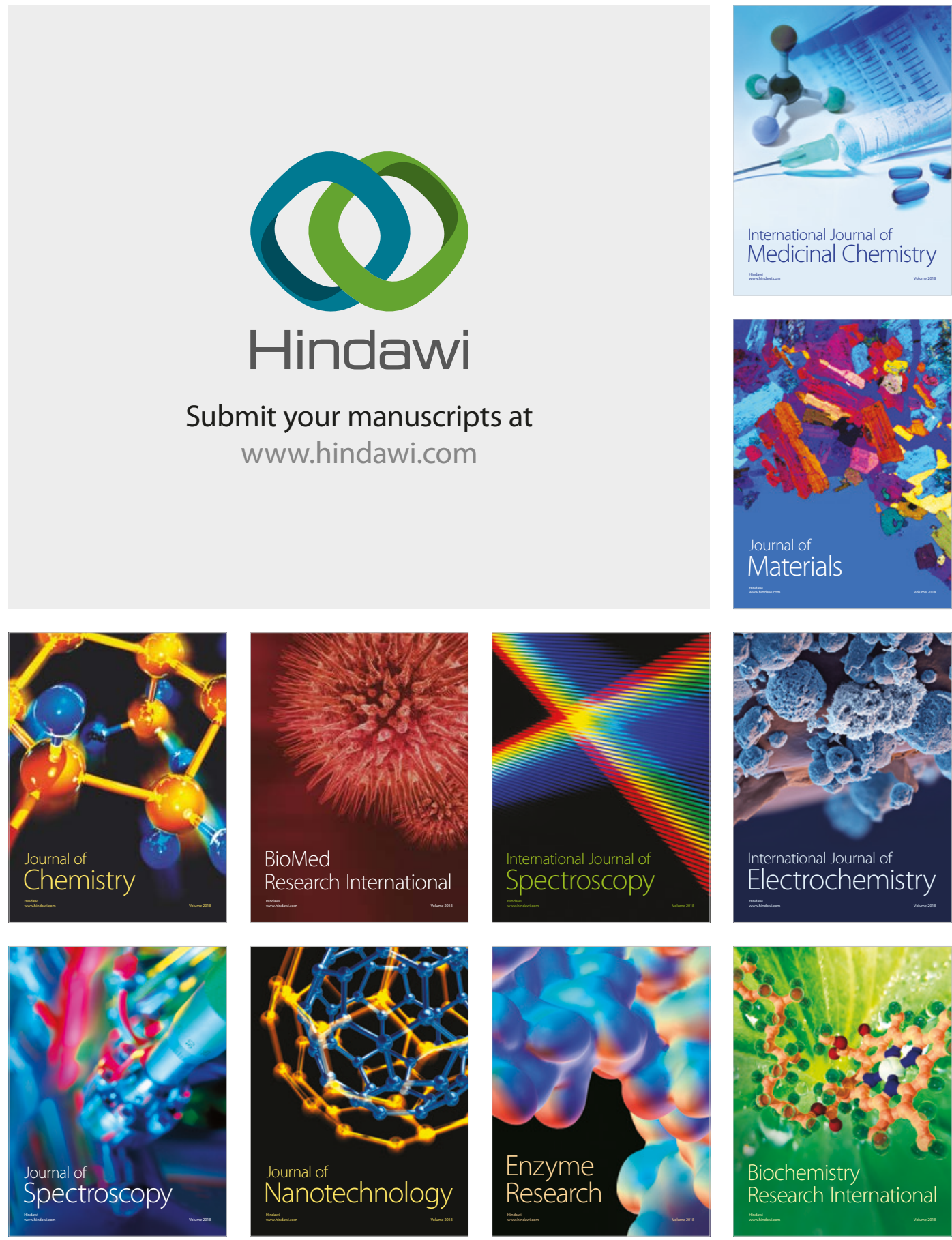
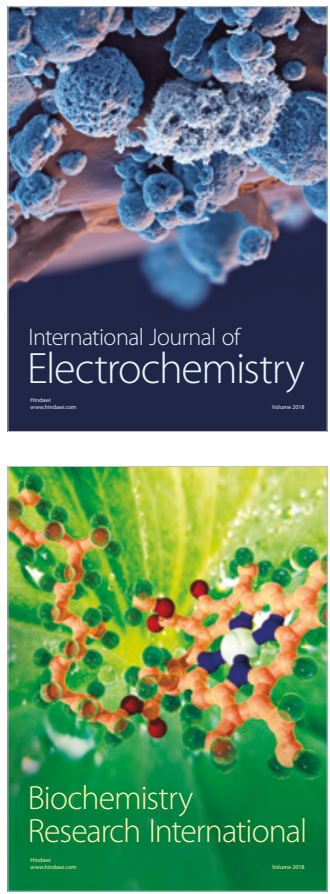